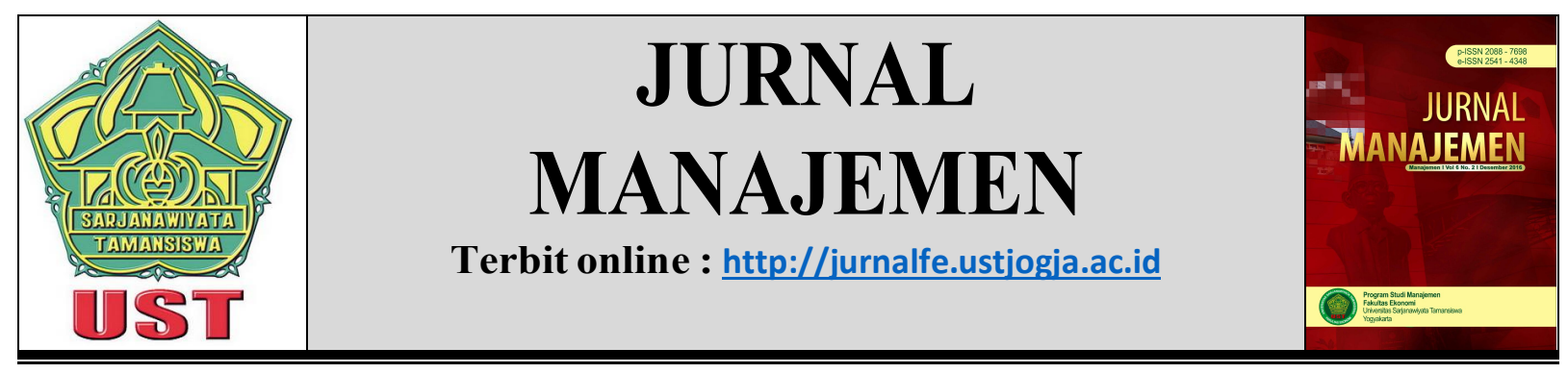

\title{
MARKET ORIENTATION, ENTREPRENEURIAL ORIENTATION DAN BUSINESS PERFORMANCE PADA USAHA MIKRO KECIL DI DESA WISATA DAERAH ISTIMEWA YOGYAKARTA
}

\author{
Adhi Prakosa ${ }^{1}$ \\ Ahsan Sumantika ${ }^{2}$ \\ ${ }^{1,2}$ Universitas PGRI Yogyakarta
}

Korespondensi: adhi27prakosa@gmail.com

\begin{tabular}{ll}
\hline Informasi Naskah & Abstrak \\
\hline Diterima: & This study aims to test relationships between market orientation, \\
$26 \mathrm{Mei}$ & entrepreneurial orientation, and business performance in small \\
Revisi: & firm that located in tourist village in Yogyakarta. Independent \\
$28 \mathrm{Mei}$ & variable is the market orientation, and entrepreneurial \\
Terbit: & orientation. The dependent variable is business performance. \\
$5 \mathrm{Juni}$ & The data collection is done directly by using a survey \\
\hline Kata Kunci: Market & questionnaire. Hypothesis testing is done using multiple linear \\
Orientation,Entrepreneurial & regression. Results can be concluded that the market orientation, \\
Orientation, Business & and entrepreneurial orientation affects the business performance \\
Performance, Tourist & \\
Village, Small And Medium & \\
Size Enterprise &
\end{tabular}

\section{PENDAHULUAN}

Perkembangan dunia pariwisata di Indonesia beberapa tahun ini mengalami peningkatan yang signifikan. Kunjungan wisatawan baik domestik atau wisatawan asing semakin banyak, dan pemerintah bersama pihak swasta telah mendorong berkembangnya desa-desa wisata di Indonesia. Sebagai negara kepulauan yang luas, potensi pariwisata sangatlah banyak. Pembukaan desa-desa wisata diharapkan memberikan peluang dan dapat membantu menumbuhkan ekonomi masyarakat sehingga mengurangi kemiskinan. Desa wisata merupakan obyek wisata yang menarik banyak wisatawan lokal maupun mancanegara karena memiliki keunikan tersendiri.

Bagi desa wisata yang berlokasi di Daerah Istimewa Yogyakarta, usaha yang bertumbuh adalah usaha skala mikro kecil (UMK). Masalah yang terjadi pada UMK adalah 
produktivitas yang rendah karena sumber daya manusia yang terbatas, sehingga kinerja bisnis mereka sulit untuk berkembang. Mereka berusaha keras untuk menarik kunjungan wisatawan baik wisatawan domestik atau asing agar dapat bertahan di tengah persaingan. Untuk meningkatkan potensi pariwisata artinya perlu dilakukan strategi-strategi pemasaran seperti citra merek, periklanan, promosi, strategi bauran pemasaran (marketing mix) dan lain sebagainya. Kemampuan ini erat kaitannya dengan orientasi pasar dan orientasi kewirausahaan.

Orientasi pasar atau disebut dengan market orientation berkaitan dengan kemampuan suatu organisasi bisnis untuk dapat memahami perubahan lingkungan yang terjadi. Perubahan lingkungan dapat diartikan bahwa mereka fokus pada kondisi terkini yang terjadi di pasar (Kohli \& Jaworski, 1990) sehingga dapat memuaskan kebutuhan dan keinginan konsumen. Orientasi kewirausahaan atau disebut dengan entrepreneurial orientation berkaitan dengan upaya untuk mengidentifikasi dan mengeksploitasi kesempatan (Lumpkin \& Dess, 1996). Kemampuan melihat peluang dan berani dalam mengambil keputusan untuk mengembangkan perusahaan, erat kaitannya dengan Entrepreneurial Orientation (EO). EO akan mempengaruhi kinerja bisnis melalui kegiatan pemasaran, dan dapat dibagi dalam dimensi inovatif, proaktif, dan pengambilan resiko (Kajalo \& Lindblom, 2015), walaupun sejauh mana pendekatan kewirausahaan terhadap pembuatan strategi berguna, seringkali akan bergantung pada kondisi organisasi atau lingkungan dimana keputusan tersebut dibuat (Lumpkin \& Dess, 2001).

Penelitian sebelumnya menunjukkan bahwa market orientation dan entrepreneurial orientation berpengaruh secara positif dan signifikan terhadap kinerja perusahaan di negaranegara berkembang (Gruber-Muecke \& Hofer, 2015). Di industri yang lebih kecil (small retailer), penelitian yang dilakukan oleh Kajalo \& Lindblom (2015) menunjukkan bahwa market orientation tidak mempunyai pengaruh signifikan terhadap kinerja. Market orientation tidak berpengaruh langsung kepada kinerja perusahaan karena dimediasi oleh kemampuan pemasaran (Murray, Gao, \& Kotabe, 2011). Penelitian lain menunjukkan bahwa entrepreneurial orientation mempunyai pengaruh langsung dan tidak langsung terhadap kinerja perusahaan terutama di small retail (Kajalo \& Lindblom, 2015). Demikian juga penelitian yang dilakukan oleh Kocak, Carsrud, \& Oflazoglu (2017) menunjukkan bahwa entrepreneurial orientation mempunyai pengaruh langsung atau tidak langsung terhadap kinerja perusahaan.

Pada organisasi bisnis, dengan adanya orientasi pasar dan orientasi kewirausahaan diharapkan dapat meningkatkan kinerja bisnis usaha mikro kecil. Kinerja bisnis ini yang dapat diukur dengan berbagai macam indikator. Orientasi kewirausahaan secara positif juga dipengaruhi oleh capaian pendidikan dan pengalaman bisnis pemilik usaha skala kecil (Altinay \& Wang, 2011). Saat ini, penelitian mengenai UMK sudah banyak dilakukan, akan tetapi penilaian mengenai kinerja bisnis yang dipengaruhi oleh aspek orientasi pasar (market orientation) dan orientasi kewirausahaan (entrepreneurial orientation) dalam konteks pariwisata khususnya desa wisata masih jarang dilakukan. Untuk itu, penelitian ini hanya akan mengambil objek penelitian hanya pada para UMK khusunya pada desa wisata di Yogyakarta. Penelitian ini bertujuan untuk meneliti bagaimana kontribusi market orientation dan entrepreneurial orientation pada pelaku usaha mikro kecil di desa wisata terhadap kinerja bisnis khususnya di desa wisata Daerah Istimewa Yogyakarta.

\section{KAJIAN PUSTAKA DAN HIPOTESIS Market Orientation dan Business Performance}

Market orientation (MO) berkaitan dengan kemampuan suatu organisasi bisnis untuk dapat memahami perubahan lingkungan yang terjadi. Persaingan usaha yang semakin ketat 
membuat kemampuan ini harus dimiliki oleh setiap organisasi bisnis tak terkecuali yang berskala mikro. Perubahan lingkungan dapat diartikan bahwa mereka dapat memahami kondisi terkini yang terjadi di pasar. Hal ini bisa dihubungkan dengan perubahan perilaku pelanggan sehingga perusahaan perlu kemampuan adaptasi. Salah satu bentuknya adalah berusaha selalu dekat dengan pasar.

Mendekati pasar memerlukan perancangan dan pemilihan strategi yang tepat. Untuk itulah organisasi bisnis yang baik adalah mereka yang memiliki kemampuan untuk merancang strategi pemasaran yang sesuai dengan perubahan lingkungan. Strategi ini sebaiknya dirancang untuk memuaskan pelanggan. Memuaskan pelanggan berarti mengetahui kebutuhan dan keinginan mereka. Kebutuhan dan keinginan ini tentunya akan terus berkembang seiring perubahan lingkungan yang terus-menerus. Organisasi bisnis seharusnya dapat berorientasi terhadap pelanggannya. Hal ini akan berdampak secara langsung terhadap kinerja bisnis mereka.

Business performance (BP) adalah kinerja bisnis suatu perusahaan. Baker and Sinkula (2009) dalam Kajalo \& Lindblom (2015) mengatakan bahwa orientasi pasar berpengaruh langsung pada profitabilitas perusahaan kecil. Orientasi pasar yang kuat akan berdampak pada kinerja bisnis perusahaan, dan menghasilkan profitabilitas tinggi (Kumalaningrum, 2012). Hal ini apabila dibandingkan, bagi perusahaan yang memiliki orientasi pasar yang lemah kemungkinan mereka tidak menghasilkan profit margin yang lebih tinggi. Profitabilitas merupakan sebuah ukuran yang digunakan untuk mengukur sejauh mana suatu perusahaan memperoleh keuntungan.

Semakin tinggi profitabilitas suatu perusahaan maka semakin baik kemampuan sebuah perusahaan menghasilkan laba. Profitabilitas dapat diukur dengan beberapa cara, sebagai contoh menghitung profitabilitas dengan nilai earning per share (EPS), return of equity, return of investment (ROI), growth (pertumbuhan laba dan penjualan) dan lain sebagainya. Selain menggunakan ukuran-ukuran rasio, menggunakan kuesioner skala Likert untuk mengukur kinerja perusahaan bisa dilakukan seperti pada penelitian ini.

Salah satu cara mencapai profitabilitas tinggi adalah dengan memiliki lini pemasaran yang baik. Melakukan promosi yang efektif pada produk-produk yang dimiliki sehingga dapat memenuhi kebutuhan dan keinginan konsumen. Perusahaan dengan orientasi pasar yang kuat akan memiliki kemampuan lebih cepat untuk memahami pasar sehingga berusaha meningkatkan kinerja bisnisnya. Menurut Kohli \& Jaworski (1990), orientasi pasar yang muncul di lapangan pada dasarnya adalah pandangan dari dua pilar di dalam konsep pemasaran, yaitu fokus pada konsumen dan koordinasi. Ini menunjukkan bahwa orientasi pasar memerlukan satu atau lebih departemen untuk terlibat dalam kegiatan yang diarahkan untuk memahami kebutuhan pelanggan saat ini dan di masa depan, serta faktor-faktor yang mempengaruhi mereka. Berdasarkan literatur di atas maka dihipotesiskan

Hipotesis 1 : Market orientation berpengaruh positif terhadap business performance pada usaha mikro kecil di desa wisata

\section{Entrepreneurial Orientation dan Business Performance}

Suatu organisasi bisnis pastinya memiliki seorang pemimpin. Pemimpin tersebut adalah seseorang yang memiliki kewenangan dan bertindak sebagai pengambil keputusan. Pemimpin yang baik adalah seorang yang bisa melihat peluang-peluang baru. Kemampuan melihat peluang dan berani dalam mengambil keputusan untuk mengembangkan perusahaan, erat kaitannya dengan entrepreneurial orientation (EO). Lumpkin dan Dess (1996) dalam 
Kumalaningrum (2012) mendefinisikan Entrepreneurial Orientation sebagai suatu metode, praktik, dan gaya pengambilan keputusan para manajer yang mengarah pada orientasi kewirausahaan.

Entrepreneurial Orientation akan mempengaruhi kinerja bisnis melalui kegiatan pemasaran, dan dapat dibagi dalam dimensi inovatif, proaktif, dan pengambilan resiko (Kajalo \& Lindblom, 2015). Inovatif adalah kecenderungan untuk terlibat dalam kreativitas dan eksperimen melalui pengenalan produk atau layanan baru serta kepemimpinan teknologi melalui penelitian dan pengembangan, proaktif adalah perspektif untuk mencari peluang dan berwawasan ke depan yang ditandai dengan diperkenalkannya produk dan layanan baru untuk menghadapi kompetisi dan bertindak untuk mengantisipasi permintaan masa depan, pengambilan resiko adalah tindakan berani menjelajah ke dalam hal yang tidak diketahui dan mengerahkan sumber daya yang signifikan untuk usaha di lingkungan yang tidak pasti. (Rauch, Wiklund, Lumpkin, \& Frese, 2009).

Kewirausahaan tidak dapat dipisahkan dari pengambilan keputusan yang beresiko. Mengenai risiko dalam pengambilan keputusan, March \& Shapira (1987) berpendapat bahwa manajer memiliki reaksi normatif terhadap risiko, pengambilan risiko justru sangat penting untuk inovasi, dan pengambilan risiko seharusnya menghasilkan keputusan yang baik. Lumpkin \& Dess (1996) menambahkan dimensi lainnya dalam entrepreneurial orientation yaitu autonomy, dan competitive aggressiveness. Autonomy yaitu tindakan independen yang dilakukan oleh wirausahawan, sedangkan competitive aggressiveness adalah intensitas usaha yang dilakukan perusahaan untuk mengungguli pesaing dan ditandai dengan respon yang agresif terhadap ancaman persaingan.

Seorang pemimpin perusahaan, baik yang berskala besar maupun kecil akan menghadapi persaingan dari kompetitor setiap saat. Persaingan yang ketat di dunia usaha membuat setiap organisasi bisnis harus aktif dalam mengamati pesaing. Knight dan Cavusgil (2004) dalam Ismail, Md Isa, Alam, \& Ahmad, (2016) mengatakan bahwa orientasi kewirausahaan sangat penting bagi perusahaan kecil karena mendorong mereka untuk mengembangkan barang berkualitas tinggi, khas, dan berteknologi maju. Saat mengembangkan inovasi, seorang pemimpin harus mengambil resiko dalam mengambil keputusan. Resiko yang dihadapi adalah ketidakpastian.

Munculnya pesaing baru tentu akan mempengaruhi peta persaingan, dan mungkin berdampak pada kinerja bisnis perusahaan, sehingga diperlukan figur pemimpin yang cakap dalam mengatur perusahaan. Aspek demografis seperti tingkat pendidikan mempengaruhi kemampuan seorang pemimpin perusahaan. Sejalan dengan ini, penelitian sebelumnya menemukan bahwa pencapaian pendidikan seorang pemimpin membantu mereka mengembangkan keterampilan, tidak hanya dalam mengumpulkan data intelijen pasar tetapi juga untuk analisis informasi dan tindakan (Altinay \& Wang, 2011). Untuk itu, menghadapai persaingan bisnis, ketidakpastian lingkungan, dan perubahan teknologi yang begitu cepat, membuat setiap perusahaan harus mampu memberikan respon yang cepat pula. Menjadi penting untuk suatu organisasi bisnis memiliki orientasi kewirausahaan yang dimiliki oleh para pengambil keputusan di dalam organisasi mereka. Berdasarkan penelitian sebelumnya, faktor Market Orientation dan Entrepreneurial Orientation memiliki korelasi yang kuat dan signifikan dengan kinerja perusahaan, sehingga sebuah perusahaan tidak hanya berorientasi di pasar saja akan tetapi juga bertindak sebagai sebuah organisasi wirausaha (Gruber-Muecke \& Hofer, 2015). Penting bagi usaha mikro mengembangkan orientasi pasar dan kemampuan wirausaha pada sumber daya manusianya agar berdampak pada peningkatan kinerja bisnis 
mereka. Berdasarkan penjelasan dari literatur di atas maka dapat dihipotesiskan:

Hipotesis 2 : Entrepreneurial orientation berpengaruh positif terhadap business performance pada usaha mikro kecil di desa wisata.

Berdasarkan hipotesis 1 dan 2 kemudian peneliti membentuk hipotesis 3 sebagai berikut: Hipotesis 3 : Market orientation dan entrepreneurial orientation berpengaruh simultan terhadap Business Performance pada usaha mikro kecil di desa wisata

\section{MODEL PENELITIAN}

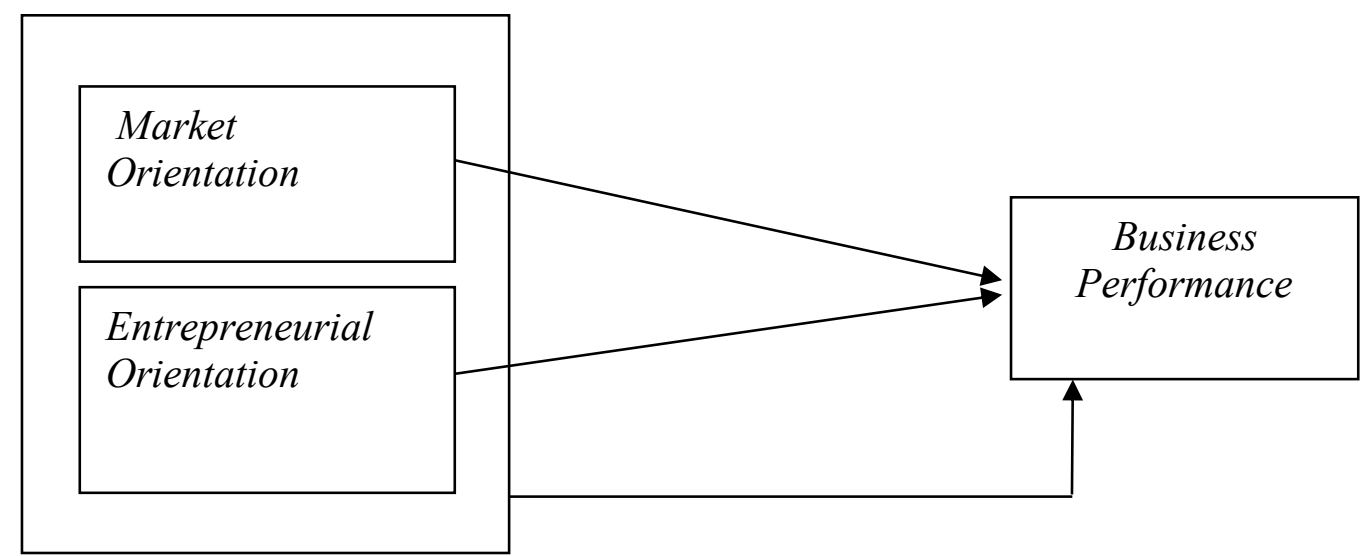

\section{Gambar 1 \\ Model Penelitian}

\section{METODE PENELITIAN}

\section{Desain Penelitian, Populasi dan Sampel}

Fokus penelitian ini adalah pada tiga variabel yaitu variabel Market Orientation dan Entrepreneurial Orientation sebagai variabel independen, dan variabel Business Performance sebagai variabel dependen. Menggunakan metode survei, data dikumpulkan melalui daftar pertanyaan pada kuesioner sehingga data yang digunakan dalam penelitian ini adalah data primer. Teknik sampling yang digunakan adalah purposive sampling yakni metode pengambilan sampel berdasarkan kriteria tertentu. Kriteria responden dalam sampel untuk penelitian ini dibatasi kepada para pelaku UMK di desa wisata di Daerah Istimewa Yogyakarta. Kriterianya sebagai berikut: 1) para pelaku UMK di desa wisata di Daerah Istimewa Yogyakarta, 2) para pelaku UMK tersebut mempunyai produk dengan ciri khas khusus di desa wisata tersebut.

\section{Analisis Data}

Tahapan sebelum dilakukan pengambilan data adalah membangun sebuah instrumen kuesioner dan menguji validitas dan reliabilitasnya. Hal ini penting agar instrumen tersebut valid dan reliabel. Validitas digunakan untuk menguji apakah instrumen yang dibangun dapat mengukur apa yang seharusnya diukur. Pengujian validitas digunakan untuk memastikan bahwa setiap item pertanyaan mengukur variabel yang akan diukur secara tepat, sedangkan reliabilitas digunakan untuk mengukur sejauh mana hasil pengukuran tetap konsisten pada konteks yang berbeda. Alat uji yang digunakan dalam uji validitas adalah analisis faktor, sedangkan alat uji yang digunakan dalam uji reliabilitas adalah dengan menggunakan Cronbach Alpha.

Item-item pertanyaan dalam kuesioner disusun dalam skala Likert yang terdiri dari 5 
skala penilaian. Jika ada pertanyaan dalam masing-masing variabel yang tidak memenuhi syarat dalam uji validitas dan reliabilitas maka pertanyaan tersebut akan dikeluarkan dari variabel penelitian. Untuk menguji hipotesis digunakan analisis regresi linear berganda. Regresi berganda digunakan untuk menguji apakah beberapa variabel (independen) mempunyai pengaruh ke variabel lainnya (dependen). Penelitian ini menggunakan variabel dependen (Y) business performance, sedangkan variabel independen $(\mathrm{X})$ yang digunakan adalah market orientation $\left(\mathrm{X}_{1}\right)$ dan entrepreneurial orientation $\left(\mathrm{X}_{2}\right)$.

\section{HASIL DAN PEMBAHASAN}

\section{Karakteristik Responden}

Berdasarkan data di atas, sebagian besar responden mayoritas berusia antara 41-50 tahun. Tingkat pendidikan terakhir responden rata-rata adalah SMA. Berikut ini adalah data demografis yang menunjukkan latar belakang responden dan disusun berdasar jenis kelamin, usia, dan pendidikan:

\section{Tabel 1}

Data Demografi Responden

\begin{tabular}{lccclc}
\hline \multicolumn{2}{c}{ Jenis Kelamin } & \multicolumn{2}{c}{ Usia } & \multicolumn{2}{c}{ Tingkat Pendidikan } \\
\multicolumn{1}{c}{ JK } & Jumlah & Usia & Jumlah & Pendidikan & Jumlah \\
\hline Laki-laki & 58 & $20-30$ & 30 & SD & 7 \\
Perempuan & 58 & $31-40$ & 32 & SMP & 15 \\
N/A & - & $41-50$ & 37 & SMA & 67 \\
& & $51-60$ & 11 & S1 & 19 \\
& & $>60$ & 3 & S2 & 2 \\
Total & & N/A & 3 & N/A & 6 \\
\hline
\end{tabular}

Sumber: Data Primer Diolah

Tabel 2

Deskripsi Usaha Responden

\begin{tabular}{lccccc}
\hline \multicolumn{1}{c}{ Lokasi } & & \multicolumn{2}{c}{ Lama Usaha } & \multicolumn{2}{c}{ Jumlah Karyawan } \\
\multicolumn{1}{c}{ Lokasi } & Jumlah & Lama & Jumlah & Karyawan & Jumlah \\
\hline Sleman & 8 & $<1$ & 1 & $0-10$ & 82 \\
Yogyakarta & 20 & $1-3$ & 18 & $11-20$ & 24 \\
Bantul & 88 & $3-5$ & 14 & $21-30$ & 7 \\
Kulon Progo & - & $5-10$ & 38 & $31-40$ & 1 \\
Gunung Kidul & - & $>10$ & 41 & $40-50$ & 1 \\
& & - & 4 & $>50$ & 1 \\
Total & 116 & Total & 116 & Total & 116 \\
\hline
\end{tabular}

Sumber: Data primer diolah

Berdasarkan data di atas, sebagian besar responden berasal dari desa wisata di daerah Bantul. Rata-rata lama usaha di atas 10 tahun, dan 5-10 tahun. Jumlah karyawan rata-rata kurang dari 10. Mengenai jenis usaha di desa wisata responden sangat bervariasi terdiri dari 
kerajinan bambu, kerajinan batik, kerajinan kulit, kerajinan kayu, kerajinan rotan, kerajinan perak, kerajinan wayang, kerajinan topeng, dan gerabah.

\section{Pengujian Instrumen}

\section{Uji Validitas}

Pengujian validitas dalam penelitian ini menggunakan analisis faktor. Item pertanyaan dalam instrumen penelitian berjumlah 25 pertanyaan. Dari hasil pengujian analisis faktor, beberapa item pertanyaan perlu dikeluarkan dari analisis. Seluruh variabel dapat dianalisis lebih lanjut karena memenuhi kriteria nilai KMO lebih besar dari 0,5 dan Bartlett's Test of Sphericity dengan tingkat signifikansi $<0,01$. Pada tabel berikut merupakan hasil analisis faktor yang menunjukkan bahwa butir-butir pertanyaan mengelompok membentuk 3 (tiga) faktor sesuai dengan jumlah variabel dalam penelitian, dan tidak terjadi cross loading. Tiap butir pertanyaan memiliki faktor loading yang tinggi yaitu lebih besar dari 0,4 sesuai dengan ketentuan yang dipersyaratkan dalam analisis faktor.

Tabel 2

Hasil Pengujian Validitas

\begin{tabular}{lccc}
\hline \multicolumn{1}{c}{ Variabel Penelitian } & \multicolumn{3}{c}{ Faktor } \\
Marketing Orientation & $\mathbf{1}$ & $\mathbf{3}$ \\
mo1 & 0,775 & & \\
mo3 & 0,731 & & \\
mo5 & 0,770 & & \\
mo7 & 0,746 & & \\
mo9 & 0,856 & & 0,728 \\
Entrepeneurial Orientation & & & 0,895 \\
eo4 & & & \\
eo10 & & & \\
Business Performance & & 0,879 & \\
bp1 & & & \\
bp2 & & & \\
\hline Sumber: Data primer diolah
\end{tabular}

Sumber: Data primer diolah

\section{Uji Reliabilitas}

Alat uji untuk mengukur reliabilitas adalah Cronbach Alpha. Jika nilai cronbach alpha di atas 0,6 maka instrumen penelitian dapat dinyatakan reliabel. Item-item pertanyaan yang dinyatakan tidak valid dalam uji validitas sebelumnya dikeluarkan dalam uji reliabilitas. Berikut ini adalah hasil dari uji reliabilitas untuk masing-masing variabel:

Tabel 3

Hasil Pengujian Reliabilitas

\begin{tabular}{lll}
\hline \multicolumn{1}{c}{ Variabel } & $\begin{array}{c}\text { Jumlah } \\
\text { Item }\end{array}$ & $\begin{array}{c}\text { Cronbach's } \\
\text { Alpha }\end{array}$ \\
\hline Market Orientation (X1) & 5 & 0,881 \\
Entrepreneurial Orientation (X2) & 2 & 0,682 \\
\hline
\end{tabular}




\begin{tabular}{lll}
\hline Bussiness Performance (Y) & 2 & 0,888 \\
\hline
\end{tabular}

Sumber: Data primer diolah

Berdasarkan tabel di atas masing-masing variabel mempunyai nilai Cronbach Alpha lebih dari 0,6 maka instrumen dalam penelitian ini dapat dikatakan konsisten dan reliabel, sehingga dapat dilakukan pengujian hipotesis.

\section{Pengujian Hipotesis dan Pembahasan}

Pengujian hipotesis pertama dan kedua digunakan analisis regresi linear berganda. Regresi berganda digunakan untuk menguji apakah beberapa variabel (independen) mempunyai pengaruh ke variabel lainnya (dependen). Variabel dependen (Y) yang digunakan adalah adalah business performance dan variabel independen $(\mathrm{X})$ adalah market orientation $\left(\mathrm{X}_{1}\right)$ dan entrepreneurial orientation $\left(\mathrm{X}_{2}\right)$.

Hipotesis diterima jika nilai signifikansi ( $p$ value) kurang dari 0.05 dan koefisien regresi bernilai positif. Untuk selengkapnya berikut ini tabel yang menjelaskan hasil uji regresi :

\section{Tabel 4}

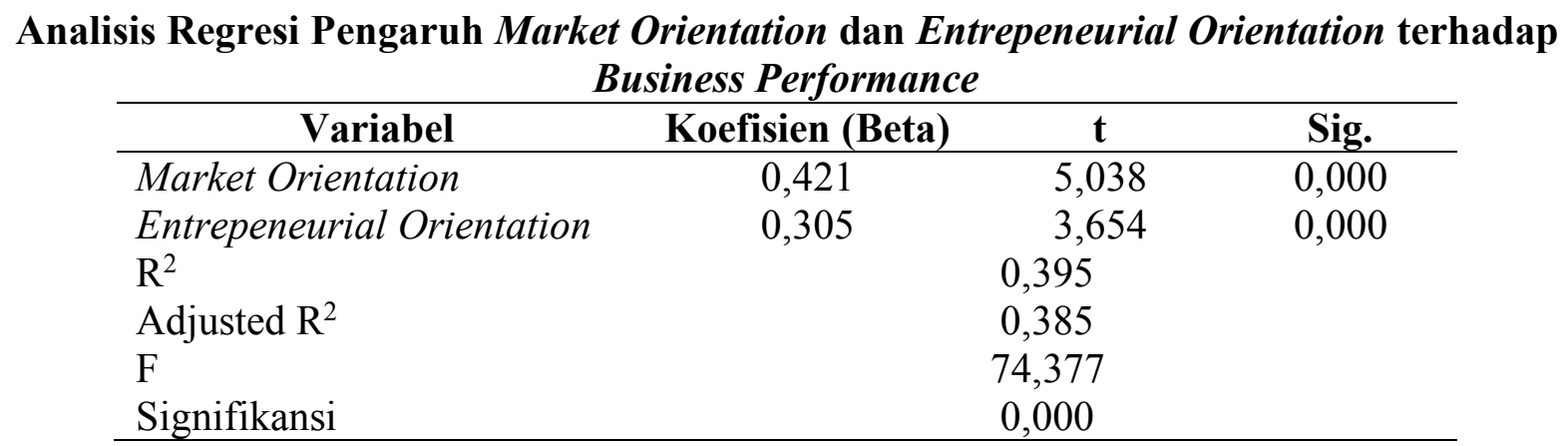

Sumber: Data primer diolah

Hipotesis 1: Market orientation berpengaruh positif terhadap business performance pada usaha mikro kecil di desa wisata.

Berdasarkan analisis regresi di atas maka dapat dinyatakan bahwa hipotesis pertama yang menyatakan "Market orientation berpengaruh positif terhadap business performance pada usaha mikro kecil di desa wisata" diterima karena mempunyai nilai signifikansi di bawah 0,05

Hipotesis 2: Entrepreneurial orientation berpengaruh positif terhadap business performance pada usaha mikro kecil di desa wisata.

Berdasarkan analisis regresi di atas maka dapat dinyatakan bahwa hipotesis kedua yang menyatakan "Entrepreneurial orientation berpengaruh positif terhadap business performance pada usaha mikro kecil di desa wisata" diterima karena mempunyai nilai signifikansi di bawah 0,05. Menurut Guzman \& Lopez-Torres (2016) bahwa sifat proaktif, berani mengambil resiko, dan inovasi merupakan faktor yang berpengaruh kuat terhadap orientasi kewirausahaan dalam bisnis UKM.

Nilai R Square sebesar 0,395 menunjukkan bahwa variasi variabel independen dapat menjelaskan variasi variabel dependen sebesar 39,5 persen sementara sisanya sebesar 60,5 persen dijelaskan oleh lebih banyak variabel-variabel lain di luar model penelitian. Secara umum, semakin baik market orientation dan entrepreneurial orientation maka semakin baik 
business performance yang ditunjukkan dengan koefisien regresi positif. Berdasarkan besar pengaruhnya, market orientation lebih berpengaruh mempunyai pengaruh yang paling signifikan dibanding entrepeneurial orientation yang ditunjukkan dengan nilai t hitung yang lebih tinggi

Hipotesis 3: Market orientation dan entrepreneurial orientation berpengaruh simultan terhadap business performance pada usaha mikro kecil di desa wisata

Untuk menguji hipotesis ketiga digunakan uji $\mathrm{F}$. Uji $\mathrm{F}$ digunakan untuk menguji apakah variabel-variabel independen yang diuji mempunyai pengaruh ke variabel dependen. Hipotesis diterima jika nilai signifikansi ( $p$ value) kurang dari 0.05 . Berdasarkan uji $\mathrm{F}$ di atas maka dapat dinyatakan bahwa hipotesis ketiga diterima karena mempunyai nilai signifikansi di bawah 0.05

\section{PENUTUP}

Penelitian ini memperkuat teori bahwa organisasi yang memiliki orientasi kepada pasar dan memiiliki pemahaman terhadap konsumennya akan bertahan menghadapi persaingan dan kemajuan zaman. Orientasi terhadap pasar bukan merupakan faktor utama, akan tetapi orientasi kewirausahaan yang dimiliki oleh pemilik usaha dapat melengkapi bisnis tersebut dengan tujuan yang lebih jelas. Saat organisasi bisnis mampu mengenali konsumennya, maka akan memudahkan mereka dalam memberikan pelayanan yang terbaik. Menentukan strategi pemasaran seperti misalnya memutuskan segmen mana yang akan dilayani, target pasar sebagai sasaran, dan memposisikan produk mereka di benak konsumen dapat dipahami lebih mudah oleh organisasi bisnis yang memiliki orientasi pasar dan orientasi kewirausahaan yang kuat. Menurut Basso, Fayolle, \& Bouchard (2009) orientasi kewirausahaan ditandai dengan pengambilan keputusan yang cenderung lebih memiliki keberanian dalam hal kemandirian, inovasi, pengambilan resiko, dan lebih agresif menghadapi pesaing. Organisasi akan memiliki inisiatif terhadap peluang-peluang yang nampak di masa kini maupun masa datang. Tingginya tingkat orientasi kewirausahaan yang dimiliki oleh pemilik bisnis akan berpengaruh terhadap keaktifan organisasi dalam menerapkan langkah-langkah yang berdampak pada kemajuan dalam bisnis sehari-hari (Guzman \& Lopez-Torres, 2016). Jika orientasi kewirausahaan ini mengakar kuat dalam organisasi, maka akan berkaitan dengan tanggapan mereka terhadap perubahan lingkungan yang terjadi, baik di masa kini maupun di masa yang akan datang. Maka dari itu, organisasi bisnis harus melakukan penyesuaian-penyesuaian yang sejalan dengan kebutuhan dan keinginan konsumen. Dengan demikian, orientasi bisnis maupun orientasi kewirausahaan semuanya bermuara untuk menciptakan konsumen yang loyal terhadap perusahaan.

\section{REFERENSI}

Altinay, L., \& Wang, C. L. (2011). The influence of an entrepreneur's socio-cultural characteristics on the entrepreneurial orientation of small firms. Journal of Small Business and Enterprise Development, 18(4), 673-694. http://doi.org/10.1108/14626001111179749

Basso, O., Fayolle, A., \& Bouchard, V. (2009). Entrepreneurial orientation : the making of a concept. Entrepreneurship and Innovation, 10(November), 313-321. http://doi.org/10.5367/000000009790012327

Gruber-Muecke, T., \& Hofer, K. M. (2015). Market orientation, entrepreneurial orientation and performance in emerging markets. International Journal of Emerging Markets, 10(3), 560-571. http://doi.org/10.1108/IJoEM-05-2013-0076

Guzman, G. M., \& Lopez-Torres, G. C. (2016). Entrepreneurial Orientation Level in Mexican 
SMEs Entrepreneurial Orientation Level in Mexican SMEs. Journal of Management and Sustainability, 6(April). http://doi.org/10.5539/jms.v6n2p89

Ismail, M. D., Md Isa, A., Alam, S. S., \& Ahmad, M. (2016). Market orientation , entrepreneurship orientation, relationship commitment and communication among SME exporters in Malaysia. GEOGRAFIA OnlineTM Malaysian Journal of Society and Space, 1(1), 19-28. Retrieved from https:/www.emich.edu/regents/meetings/2015/meeting061615/section1761615.pdf

Kajalo, S., \& Lindblom, A. (2015). Market orientation, entrepreneurial orientation and business performance among small retailers Sami. International Journal of Retail \& Distribution Management, 43(7), 580-596.

Kohli, A. K., \& Jaworski, B. J. (1990). Market Orientation: The Construct, Research Propositions, and Managerial Implications. Journal of Marketing, 54(April), 1-18.

Kumalaningrum, M. P. (2012). Market Orientation , Entrepreneurial Orientation , Innovation Success, Dan Profitabilitas Usaha Kecil Dan Menengah. Jurnal Akuntansi Dan Manajemen JAM, 23(1), 13-25.

Lumpkin, G. T., \& Dess, G. G. (1996). Clarifying the Entrepreneurial Orientation Construct and Linking it to Performance. Academy of Management Review, 21(1), 135-172.

Lumpkin, G. T., \& Dess, G. G. (2001). Linking two dimensions of entrepreneurial orientation to firm performance : the moderating role of environment and industry life cycle. Journal of Business Venturing, 16(5), 429-451.

March, J. G., \& Shapira, Z. (1987). Managerial Perspectives on Risk and Risk Taking. Management Science, 33(11), 1404-1418. http://doi.org/10.1287/mnsc.33.11.1404

Murray, J. Y., Gao, G. Y., \& Kotabe, M. (2011). Market orientation and performance of export ventures: The process through marketing capabilities and competitive advantages. Journal of the Academy of Marketing Science, 39(2), 252-269. http://doi.org/10.1007/s11747-0100195-4

Rauch, A., Wiklund, J., Lumpkin, G. T., \& Frese, M. (2009). Entrepreneurial orientation and business performance: An assessment of past research and suggestions for the future. Entrepreneurship: Theory and Practice, 33(3), 761-787. http://doi.org/10.1111/j.15406520.2009.00308.x 